\title{
VARIATION AND DEVELOPMENTAL CHANGE IN ACTIVITY OF GREGARIOUS CATERPILLARS, HEMILEUCA LUCINA (SATURNIIDAE)
}

\author{
By Jennifer C. Cornell ${ }^{1}$, Nancy E. Stamp ${ }^{2}$, \\ and M. Deane Bowers ${ }^{1}$
}

\section{INTRODUCTION}

Variation in behavior of individuals within an aggregation may result in a nominal division of labor or roles (Wilson, 1971). Individuals may play a particular role throughout the course of development or change roles often. Such variation seems to occur in tent caterpillars of the genus Malacosoma (Lasiocampidae) (M. californicum pluviale, Wellington, 1957; M. disstria, Laux, 1962 (as $M$. neustria), Greenblatt and Witter, 1976; M. americanum, Edgerly and Fitzgerald, 1982). Evidence for permanent polyethism (in terms of active or inactive individuals) was reported for $M$. c. pluviale by Wellington (1957) but was not found by Myers (1978), and Wellington's statistical analysis has been criticized (Papaj and Rausher, 1983). In other tent caterpillar species, individuals were not consistently active or inactive but shifted from one to the other state over a few days (Laux 1962; Greenblatt and Witter, 1976; Edgerly and Fitzgerald, 1982). Nonetheless, those larvae that were currently active played a critical role in determining the foraging pattern of the aggregation. For instance, small subgroups of $M$. americanum larvae left the tent before the main body of caterpillars, fed, and returned, depositing a fresh recruitment trail that the other larvae then followed to the feeding site (Fitzgerald, 1980).

To date, only Malacosoma species have been investigated for behavioral variation among larvae in aggregations even though many gregarious species exhibit distinct foraging patterns where individuals of various activity levels might be important. Furthermore, none of the Malacosoma studies assessed activity instar by

'Museum of Comparative Zoology, Harvard University, Cambridge, MA 02138, USA

${ }^{2}$ Department of Biological Sciences, State University of New York, Binghamton, NY 13901, USA

Manuscript received by the editor February 24, 1988. 
instar, which might be expected to change as mobility increases with larval size and as availability of food and presence of predators changes through the larval season. Larvae of the buckmoth, Hemileuca lucina Hy. Edw. (Saturniidae), provide an excellent example for comparison with tent-making species. $H$. lucina larvae lay silk trails, probably with a chemical marker, as do $H$. oliviae (Capinera, 1980) and move with tandem trail-following. $H$. lucina larvae often defoliate portions of the hostplant, Spiraea latifolia (Ait.) Borkh. (Rosaceae) and the aggregations are then forced to move to new feeding sites. Even newly-hatched larvae move substantial distances relative to their size to find food (Bowers and Stamp, unpubl. data). Larvae also may move distances of $3 \mathrm{~m}$ or more for thermoregulation, when they are attacked by predators and parasitoids, and when they molt (Bowers and Stamp, unpubl. data).

Transient polyethism in some tent caterpillars (e.g. M. americanum) may be associated with central-place foraging, web maintenance and group cohesion (Greenblatt and Witter, 1976; Edgerly and Fitzgerald, 1982). In contrast, $\boldsymbol{H}$. lucina larvae would be predicted to exhibit patterns of individual behavior different from Malacosoma species because $\mathrm{H}$. lucina larvae are nomadic foragers, do not construct webs and exhibit a declining tendency to aggregate over development that occurs sooner than in Malacosoma species.

Our objective was to examine individual variation in activity, using distance traveled as an index, in larvae of $\boldsymbol{H}$. lucina. Specifically, we determined: 1) whether larvae were consistently slow, fast or intermediate travelers relative to the group when tested several times within an instar, 2) whether patterns of larval activity (as measured by relative distance traveled) were consistent across instars, and 3) whether larval activity was correlated with larval weight.

\section{MeThODS}

Four egg masses of $\boldsymbol{H}$. lucina were collected from a population in Dover, Massachusetts. The groups were reared separately on $S$. latifolia in petri dishes. During the first through third instars, larvae were kept in a growth chamber at $25^{\circ} \mathrm{C}$ day: $20^{\circ} \mathrm{C}$ night, with a photoperiod of $16 \mathrm{~h}$ day: $8 \mathrm{~h}$ night. For the remaining instars, larvae were reared in the laboratory at $25^{\circ} \mathrm{C}$ in large plastic containers (46 $\times 30 \times 7 \mathrm{~cm}$ ) to prevent overcrowding. 
Each larva was individually marked using a three-dot, colorcoding system with seven colors of acrylic paint (Liquitex ${ }^{\mathrm{TM}}$ ) and weighed 4 days after each molt. Reliable identification of individuals was maintained by isolating individuals just before molt, remarking them after molt and then returning them to their groups, within $12 \mathrm{hr}$ of separation from the group. Thus, larvae could be identified individually throughout their development and during testing, while remaining with their sibling groups. In contrast, other studies have isolated individuals for substantial periods (Greenblatt and Witter, 1976; Edgerly and Fitzgerald, 1982), which may alter larval behavior.

During the first through fifth instars, larvae from each group were tested for distance traveled as an index of activity. We did not test the last (sixth) instar because those larvae are not gregarious. Larvae were tested at 4 days after molting and were starved for $24 \mathrm{~h}$ prior to testing. The test arena was a petri dish (diameter $14 \mathrm{~cm}$ ) lined with a sheet of paper on which were drawn a series of concentric circles, $2.5 \mathrm{~mm}$ apart. A paper rope was suspended vertically by a string so that the bottom touched the center of the dish. The ropes were made from paper towels soaked in $50 \%$ ethanol and twisted into $300-\mathrm{mm}$ lengths. When dry, the ropes were marked in pencil at $2.5 \mathrm{~mm}$ intervals. These ropes simulated the natural form of a branch along which larvae forage. A clean rope was used for each test. A sprig of $S$. latifolia was placed at the top of the string and a heat lamp was placed $1 \mathrm{~m}$ above that to induce the larvae to travel up the rope.

At the beginning of the test, the larvae were arranged on the paper sheet in a ring around the base of the rope. Larvae faced towards the rope and were $5 \mathrm{~cm}$ from it. They then were allowed to move around the dish or up the rope for $8 \mathrm{~min}$ for the first through third instars and for $4 \mathrm{~min}$ for the fourth and fifth instars. The reduction in test time was necessary due to an increase in overall larval activity in the later instars. The rank order of all larvae on the rope and the distance each had traveled from the starting point were recorded at the midpoint and end of each trial.

Each group of larvae was tested in 5 trials during each instar. Because individual larvae could be identified throughout the tests, we were able to obtain data on behavior of individuals at several levels: 1) variation within a trial (i.e. did larvae change ranks during 
the course of a trial?); 2) variation from one trial to another within an instar (i.e. were larval ranks consistent from one trial to another?); and 3) variation from one instar to the next.

One-tailed Spearman rank correlation was used to assess the degree of changing ranks within trials by larvae (i.e. due to turning around or possibly passing one another) with 1 indicating perfect agreement between ranks (i.e. no change) and 0 indicating no agreement.

To examine whether individual larvae were consistently ranked the same with regard to distance traveled, over the five trials within an instar, we used Kendall's coefficient of concordance (W) (Conover, 1080; Edgerly and Fitzgerald, 1982). If individuals were consistently ranked the same among trials, $\mathrm{W}=1.0$, whereas if rank varied randomly from trial to trial, $\mathrm{W}=0$.

To determine whether distance traveled by individual larvae was consistent from one instar to the next, larvae were ranked on the basis of total distance traveled in 5 trials per instar and Spearman's rank correlation $\left(\mathrm{r}_{\mathrm{s}}\right)$ was used.

Frequency distributions of distances traveled by individuals within an aggregation tend to exhibit a graded series (or hierarchy), in which relatively few individuals travel far and many individuals travel relatively short distances over a short test period (e.g. Fitzgerald, 1980; Edgerly and Fitzgerald, 1982). Following the terminology and definitions of Weiner and Solbrig (1984), we believe that the analytical methods used by plant ecologists to evaluate a graded series of sizes of individuals within a population are particularly appropriate for behavioral data such as distance traveled when: 1) the aggregation yields large variation in individual distances, 2) there are relatively few large distances and many small ones, and 3) the few large distances contribute greatly to the observed pattern. Weiner and Solbrig (1984) indicate that standard measurements of skewness are inappropriate because they are designed to be insensitive to the degree of variability and only reflect the second aspect of the three listed above. Specifically in our study, it is inequality among larvae in distance traveled, not asymmetry in the distribution of distances ( (2) above), that is of biological interest here.

Therefore, the variation in distance traveled was represented graphically using Lorenz curves and evaluated using the Gini statistic (Weiner and Solbrig, 1984). Gini coefficients take into 
account all three characteristics listed above. Individuals were ranked according to total distance traveled (over 5 trials) and the cumulative percent of distance traveled plotted against the cumulative percent of the individuals per group. If all larvae traveled the same distance, a plot of this would yield a diagonal line from the origin to upper right (e.g. a Lorenz curve with a Gini coefficient $=0$ ). The degree of deviation from the diagonal is a measure of inequality and is evaluated by the Gini coefficient, where 0 indicates all individuals are equal in distance traveled and a maximum of 1 represents complete inequality (i.e. all individuals but one having a value of 0; Weiner and Solbrig 1984).

Thus, when inequalities in distance traveled were present, the Lorenz curves and Gini coefficients provided a means to assess the degree to which the inequalities change from instar to instar and relative proportion of individuals responsible for these inequalities. For example, a high Gini value would indicate that a few individuals traveled either a small distance or quite far relative to the others and those two possibilities can be distinguished by the shape of the curve.

\section{RESULTS}

Individuals usually did not change ranks after half way through a trial (Table 1), although a few individuals turned around or passed others. For half the tests (9 of 19), ranks of individuals, as determined by distance traveled, were stable from trial to trial (Kendall's coefficient of concordance, Table 2). Total distance traveled in each instar was not correlated consistently with larval weight (Table 3) and therefore we concluded that distance traveled was unrelated to larval size.

Total distance traveled by each larva was compared between instars to determine whether those inequalities in distance traveled within an instar persisted into the next one. In most instances, total distance traveled in one instar was not correlated with distance traveled in the previous instar (Table 4). When a significant correlation occurred, it was between the third and fourth instars and between the fourth and fifth instars.

The pattern of considerable variation in distance traveled among larvae is illustrated graphically by the Lorenz curves, which show the inequalities in total distance traveled in 5 trials by individuals in 
Table 1. Comparison of ranks of individuals in groups after half the test period and at the end of the test, with Spearman rank correlation $\left(r_{s}\right)$. Significance level (P) for one tailed test with $\alpha=0.05$ is shown. In this case, 1 indicates no change in ranks by individuals between the half way point and the end of the test period, and 0 represents no agreement between those ranks. In the cases below, a significant correlation indicates agreement between ranks of individuals half way through the test and their ranks at the end. Dashes represent no movement by any individuals in that trial. First instar larvae of Group D did not move so no correlation coefficient could be calculated.

\begin{tabular}{lcccc}
\hline Group & Instar & $\mathrm{n}$ & $\mathrm{r}_{\mathrm{s}}$ & $\mathrm{P}$ \\
\hline $\mathrm{A}$ & 1 & 50 & 0.641 & $<0.001^{*}$ \\
& 2 & 45 & 0.821 & $<0.001^{*}$ \\
& 3 & 43 & 0.559 & $<0.001^{*}$ \\
& 4 & 36 & 0.739 & $<0.001^{*}$ \\
B & 5 & 28 & 0.577 & $<0.001^{*}$ \\
& 1 & 50 & 0.771 & $<0.001^{*}$ \\
& 2 & 41 & 0.888 & $<0.001^{*}$ \\
& 3 & 40 & 0.842 & $<0.001^{*}$ \\
C & 3 & 37 & 0.574 & $<0.001^{*}$ \\
& 5 & 35 & 0.760 & $<0.001^{*}$ \\
& 1 & 48 & 0.876 & $<0.001^{*}$ \\
& 2 & 41 & 0.851 & $<0.001^{*}$ \\
& 3 & 38 & 0.686 & $<0.001^{*}$ \\
D & 4 & 39 & 0.933 & $<0.001^{*}$ \\
& 5 & 25 & 0.476 & $<0.006^{*}$ \\
& 1 & 50 & - & - \\
& 2 & 34 & 0.767 & $<0.001^{*}$ \\
& 3 & 35 & 0.833 & $<0.001^{*}$ \\
& 4 & 33 & 0.750 & $<0.001^{*}$ \\
\hline
\end{tabular}

*Indicates statistical significance.

groups (Fig. 1). In the first and second instars, each group had many individuals that either did not move or only traveled short distances and a few individuals that moved relatively long distances (Fig. 1A, $B, C)$. In contrast, in the third through fifth instars, inequalities still occurred but with a few individuals traveling quite short distances and a few traveling far.

But one group (D) exhibited a different pattern than the others. In 5 trials, none of the first instar larvae moved and thus there was no Gini coefficient, and in contrast to the other groups, only a few second instar larvae remained stationary (Table 5; Fig. 1D). 
Table 2. Comparison of distance traveled among 5 trials, with $n=$ number of larvae, $\mathrm{W}=$ Kendall's coefficient of concordance, and significance $(P)<0.05$ indicated by *. The null hypothesis for the Kendall test was $\mathrm{W}=0$ when distances varied randomly from trial to trial. Thus, a significantly high value indicates that distances traveled by individuals were consistent from trial to trial.

\begin{tabular}{lcccc}
\hline Group & Instar & $\mathrm{n}$ & $\mathrm{W}$ & $\mathrm{P}$ \\
\hline A & 1 & 50 & 0.307 & $>0.10$ \\
& 2 & 45 & 0.330 & $>0.05$ \\
& 3 & 43 & 0.458 & $<0.001^{*}$ \\
& 4 & 36 & 0.245 & $>0.50$ \\
B & 5 & 28 & 0.327 & $>0.10$ \\
& 1 & 50 & 0.197 & $>0.50$ \\
& 2 & 41 & 0.289 & $>0.20$ \\
& 3 & 40 & 0.479 & $<0.001^{*}$ \\
C & 4 & 37 & 0.370 & $<0.05^{*}$ \\
& 5 & 35 & 0.715 & $<0.001^{*}$ \\
& 1 & 48 & 0.402 & $<0.01^{*}$ \\
& 2 & 41 & 0.334 & $>0.05$ \\
& 3 & 38 & 0.338 & $>0.05$ \\
D & 4 & 39 & 0.326 & $>0.05$ \\
& 5 & 25 & 0.599 & $<0.001^{*}$ \\
& 1 & 50 & - & - \\
& 2 & 34 & 0.190 & $>0.50$ \\
& 3 & 35 & 0.609 & $<0.001^{*}$ \\
& 4 & 33 & 0.464 & $<0.01^{*}$ \\
& 5 & 26 & 0.428 & $<0.05^{*}$ \\
\hline
\end{tabular}

Because it was common for larvae to remain massed for several hours at a time, we could not justify ignoring that group (D) in our statistical analysis on the grounds that it was abnormal. But consequently, we could not apply the appropriate statistical test, a nonparametric two-way ANOVA which requires values in all cells, to the Gini coefficients, and a parametric test was inappropriate because it is unclear what assumptions can be made about the underlying distribution of Gini coefficients (Weiner and Solbrig, 1984). Therefore, we analyzed only instars II-V. The Gini coefficients were significantly different among instars II-V (Friedman's test, followed by multiple comparisons (Conover, 1980); Friedman $\chi^{2}=8.400, \mathrm{df}=$ $3, P=0.04$; Table 5, Fig. 1). Thus, inequalities in distances traveled decreased from instar to instar. 
Table 3. Relationship of larval weight and total distance traveled by individuals in groups. Spearman rank coefficients $\left(\mathrm{r}_{\mathrm{s}}\right)$ and probability $(\mathrm{P})$ at $\alpha=0.05$ are indicated.

\begin{tabular}{lcccl}
\hline Group & Instar & $\mathrm{n}$ & $\mathrm{r}_{\mathrm{s}}$ & $\mathrm{P}$ \\
\hline A & 1 & 48 & -0.11 & 0.48 \\
& 2 & 43 & 0.16 & 0.32 \\
& 3 & 33 & 0.27 & 0.13 \\
& 4 & 33 & 0.23 & 0.20 \\
B & 5 & 25 & 0.67 & $0.0002^{*}$ \\
& 1 & 44 & 0.24 & 0.12 \\
& 2 & 40 & 0.03 & 0.85 \\
& 3 & 38 & 0.51 & $0.001^{*}$ \\
C & 4 & 32 & -0.24 & 0.14 \\
& 5 & 34 & 0.25 & 0.15 \\
& 1 & 48 & -0.16 & 0.28 \\
& 2 & 40 & 0.45 & $0.003^{*}$ \\
& 3 & 36 & 0.33 & $0.049^{*}$ \\
D & 4 & 33 & 0.46 & $0.006^{*}$ \\
& 5 & 27 & 0.58 & $0.001^{*}$ \\
& 1 & - & - & - \\
& 2 & 29 & 0.42 & $0.02^{*}$ \\
& 3 & 24 & 0.44 & $0.03^{*}$ \\
& 4 & 25 & 0.38 & 0.06 \\
& 5 & 25 & -0.06 & 0.80 \\
\hline
\end{tabular}

*Indicates statistical significance

\section{Discussion}

In general, studies on Malacosoma species (Laux, 1962; Greenblatt and Witter, 1976; Edgerly and Fitzgerald, 1982) and Hemileuca lucina reveal only transient leaders and followers, at most. For instance, Edgerly and Fitzgerald (1982) found a significant behavioral difference among $M$. americanum larvae in only 3 of 8 colonies, and they found no correlation in activity levels across trials. In contrast to that study, we examined larval behavior more directly by following marked individuals within trials, among trials and across instars, and found that in some cases individual $\boldsymbol{H}$. lucina were consistently traveling relatively long distances across trials and instars. But no pattern emerged that would allow us to predict which individuals might lead or in which instar that might occur. For example, Group $\mathrm{C}$ had two instars in which rankings among trials were stable (i.e. some individuals were consistently traveling faster than others), showed a significant positive correlation 
Table 4. Relationship between instars for total distance traveled by marked individuals in groups. Spearman rank coefficients $\left(\mathrm{r}_{\mathrm{s}}\right)$ and probability $(\mathrm{P})$ at $\alpha=$ 0.05 are indicated.

\begin{tabular}{lcccc}
\hline Group & Instar & $\mathrm{n}$ & $\mathrm{r}_{\mathrm{s}}$ & $\mathrm{P}$ \\
\hline A & $1-2$ & 42 & 0.227 & 0.15 \\
& $2-3$ & 34 & 0.218 & 0.22 \\
& $3-4$ & 27 & 0.308 & 0.12 \\
& $4-5$ & 20 & 0.097 & 0.69 \\
B & $1-2$ & 36 & 0.156 & 0.37 \\
& $2-3$ & 36 & -0.176 & 0.31 \\
& $3-4$ & 32 & 0.668 & $0.001^{*}$ \\
& $4-5$ & 32 & 0.403 & $0.02^{*}$ \\
C & $1-2$ & 40 & 0.177 & 0.28 \\
& $2-3$ & 34 & 0.313 & 0.07 \\
& $3-4$ & 33 & 0.447 & $0.01^{*}$ \\
& $4-5$ & 27 & 0.418 & $0.03 *$ \\
D & $1-2$ & - & - & - \\
& $2-3$ & 25 & 0.369 & 0.07 \\
& $3-4$ & 23 & 0.446 & $0.03^{*}$ \\
& $4-5$ & 21 & 0.303 & 0.19 \\
\hline
\end{tabular}

*Indicates statistical significance

between larval weight and distance traveled for Instars II-V, and exhibited a significant correlation between distance traveled between instars for two such combinations. In contrast, Group A had only one instar in which rankings were stable among trials and one instar in which distance traveled was correlated with weight.

In $H$. lucina, transient polyethism occurred at several levels: 1) Over the course of a trial, larval ranks did not change; thus, leaders during a single foraging bout (represented here by a single trial) remained at the forefront. 2) In some cases, ranks of individual larvae were constant from one trial to the next within an instar. The instar in which this was most prevalent was the third (for 3 or 4 groups). However, in other cases, there was no consistency in larval ranking from trial to trial. Thus, in some groups the same individuals led a series of foraging bouts, whereas in others, the leaders varied from bout to bout. In some instances, a significant positive correlation occurred between larval weight and distance traveled, but in other cases, there was no correlation. Thus, within a foraging group, the largest larvae were sometimes the leaders, sometimes randomly distributed within the traveling group, but were never consistently the slowest (i.e. none of the negative correlation coeffi- 

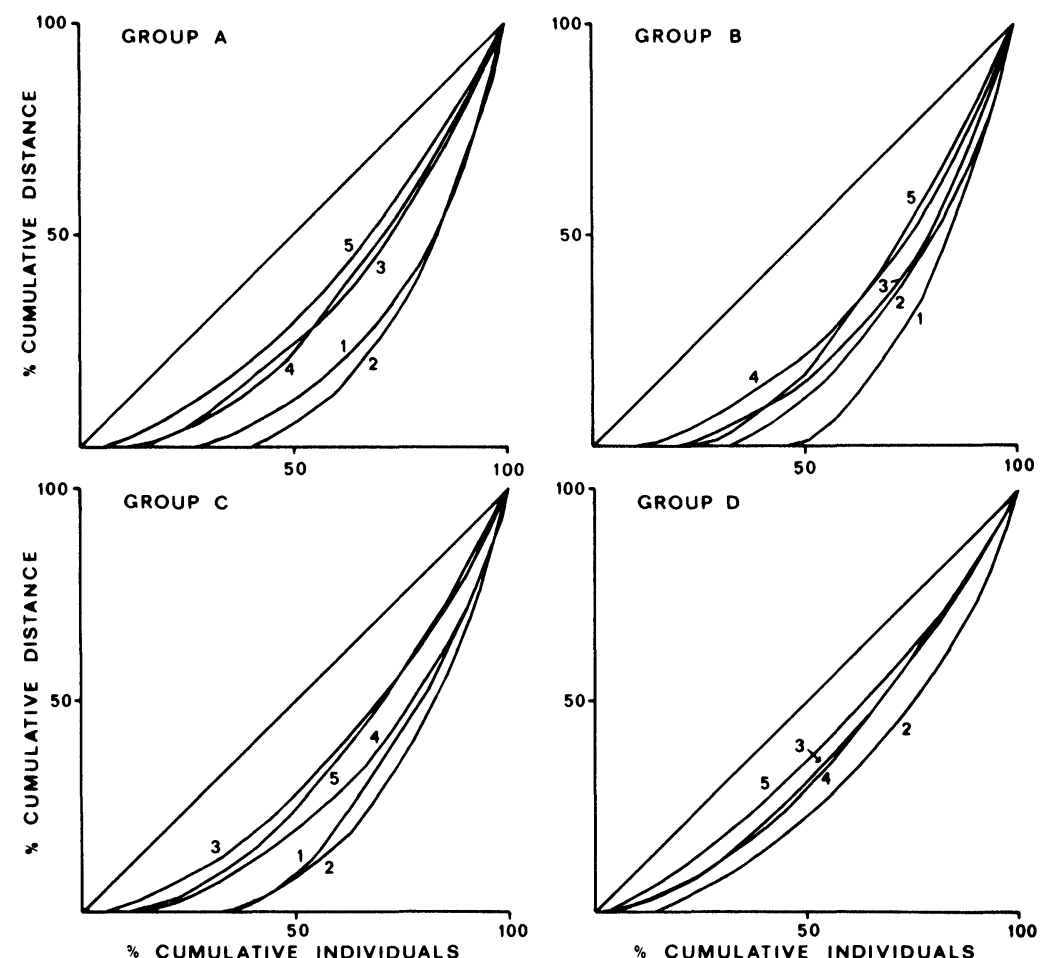

Figure 1. Pattern of inequality in distance traveled by individual larvae in sibling groups. Numbers adjacent to curves indicate the instar tested. Groups A, B, C and D are shown. First instar larvae of Group D were tested, but they remained aggregated and thus are not shown.

cients in Table 3 were significant). 3) In a quarter of the tests, ranks of individual larvae from one instar to the next remained consistent. This was primarily between the third and fourth instars (for 3 of 4 comparisons).

The Lorenz curves and Gini coefficients showed that the patterns of distance traveled by individuals changed over instars. In many cases, especially in the early instars, a few individuals moved great distances whereas others hardly moved. By the later instars, variation was still large but the inequalities (or skewness) among individuals were much less. 
Table 5. Patterns of larval variability in total distance traveled over 5 trials by larvae in groups. Gini coefficients (unbiased estimator, $\mathrm{G}^{\prime}$ ) are shown, with 0 representing complete equality and 1 indicating total inequality among larvae. First instar larvae of group D were tested but remained aggregated.

\begin{tabular}{lccccc}
\hline & \multicolumn{5}{c}{ Instar } \\
\cline { 2 - 6 } Group & 1 & 2 & 3 & 4 & 5 \\
\hline A & 0.569 & 0.612 & 0.380 & 0.365 & 0.282 \\
B & 0.640 & 0.543 & 0.486 & 0.401 & 0.418 \\
C & 0.532 & 0.583 & 0.310 & 0.450 & 0.342 \\
D & - & 0.405 & 0.279 & 0.272 & 0.212 \\
\hline
\end{tabular}

The changes in larval activity of $H$. lucina revealed by the Lorenz curves and Gini coefficients parallel other developmental changes we have observed in $H$. lucina. These larvae exhibit distinct changes in behaviors between the early and late instars. While they have strong aggregation tendencies through the third instar and remain in groups in the fourth and fifth instars unless disturbed, the tendency to aggregate declines steadily and sixth (last) instar larvae are solitary (Cornell, et al., 1987). H. lucina larvae also have a repertoire of defensive and escape behaviors that changes from one instar to the next. The most dramatic changes occurs between the third and fourth instars, from primarily defensive behaviors to largely escape behaviors (Cornell, et al., 1987). The marked inequalities in distance traveled among early instar larvae compared to the more normal distribution of distances traveled of later instars may reflect those changes in behavior, in particular the declining tendency to aggregate. Thus, a pattern of a few leaders and many slower individuals is less likely when larvae are older and less compelled to stay with the group.

Another factor contributing to the pattern of some larvae traveling long distances with others hardly moving may be digestive periods. H. lucina larvae alternate feeding with periods of inactivity, as is true for many caterpillars (Edwards, 1964; Ma, 1972; Fitzgerald, 1980; Capinera, 1980; Fitzgerald and Costa, 1986; Reynolds, et al., 1986). Hungry and, therefore, temporarily active larvae tend to stir up the group, by tactile stimulation of group members. As a result, quiescent individuals eventually follow the other, more active group members, as long as the tendency to aggregate is strong (which it is through the third molt, Cornell, et al., 1987). That tendency to aggregate, which could induce less hungry larvae to follow hungrier 
and more active individuals, may reflect advantages of staying with the group (e.g. for defense and thermoregulation). In this scenario, when the level of hunger is skewed (i.e. some individuals are hungry but most are still digesting food) we would expect a temporary pattern of leaders and followers; when the level of hunger is distributed normally among individuals in a foraging group we would expect no clear pattern of leaders and followers. Some caterpillar species alter searching behavior when the larvae are starved (Jones, 1977; Cain et al., 1985). But the idea that consistency in leadership reflects a skewed distribution in hunger-levels remains untested here because we did not attempt to assess state of hunger. However, in our study all groups were deprived of food for $24 \mathrm{~h}$ before testing. Thus, individuals should have been approaching equal hunger levels, but even with 24-h starvation, the amount of food in the gut of third and fourth instar H. lucina varies considerably (Bowers and Stamp, unpubl. data).

In these experiments, we used Lorenz curves and Gini coefficients to evaluate behavioral data, in this case skewed distributions of distance traveled. Previously, these techniques have been applied to questions of market-share and distribution of wealth in economics and biomass or size distributions in plant populations (Weiner and Solbrig, 1984, and references therein). The market-share concept does not apply to distances traveled by aggregated caterpillars per se because there does not seem to be a premium on obtaining a larger share, or in this case, being more active or traveling faster than other group members. But it is a similar situation in that the distributions of interest here tend to be skewed. That is, during the course of the experiments, the most active larvae leave the aggregation first and travel farthest, whereas other larvae remain quiescent longer and travel shorter distances. Therefore, these techniques are appropriate for our study and allow us to address the biological question of interest (i.e. what is the pattern of inequality or variation among individuals), which other measurements of skewness do not (Weiner and Solbrig, 1984). Lorenz curves and Gini statistics are applicable to other kinds of behavioral data, in particular situations where resources are limiting, and as a result, measurements of individuals yield a skewed distribution (e.g. number of matings, number of offspring). 


\section{ACKNOWLEDGMENTS}

We thank J. Edgerly, T. Fitzgerald and B. Waldman for comments on the manuscript. JCC and MDB were supported by the Clark Fund of Harvard University and NSF grant BSR-8307353 to MDB, and NES by a postdoctoral fellowship from the University of California at Davis.

\section{References Cited}

Cain, M. L., J. Eccleston, P. M. Kareiva.

1985. The influence of food plant dispersion on caterpillar searching success. Ecol. Entomol. 10: 1-7.

CAPINERA, J. L.

1980. A trail pheromone from silk produced by larvae of the range cterpillar Hemieluca oliviae (Lipidoptera: Saturniidae) and observations on aggregation behavior. J. Chem. Ecol. 6: 655-664.

CoNover, W. J.

1980. Practical nonparametric statistics, 2nd ed. John Wiley \& Sons (New York). 493.

Cornell, J. C., N. E. Stamp, M. D. Bowers.

1987. Developmental change in aggregation, defense and escape behavior of buckmoth caterpillars, Hemileuca lucina (Saturniidae). Behav. Ecol. Sociobiol. 20: 383-388.

Edgerly, J. S. AND T. D. FitzGerald.

1982. An investigation of behavioral variability within colonies of the eastern tent caterpillar Malacosoma americanum (Lepidoptera: Lasiocampidae). J. Kansas Entomol. Soc. 55: 145-155.

EDWARDS, D. $\mathbf{K}$.

1964. Activity rhythms of lepidopterous defoliator II. Halisidota argentata Pack. (Arctiidae), and Nepytia phantasmaria Stkr. (Geometridae). Can. J. Zool. 42: 939-958.

FitzGerald, T. D.

1976. Trail marking by larvae of the eastern text caterpillar. Science 154: 961-963.

Fitzgerald, T. D.

1980. An analysis of daily foraging patterns of laboratory colonies of the eastern tent caterpillar, Malacosoma americanum (Lepidoptera: Lasiocampidae). Can. Entomol. 112: 731-738.

Fitzgerald, T. D. and E. M. Gallagher.

1976. A chemical trail factor from the silk of the eastern tent caterpillar, Malacosoma americanum (Lepidoptera: Lasiocampidae). J. Chem. Ecol. 2: 187-193.

Fitzgerald, T. D. AND J. T. Costa.

1986. Trail-based communication and foraging behavior of young colonies of 
forest tent caterpillars (Lepidoptera: Lasiocampidae). Ann. Entomol. Soc. Am. 79: 999-1007.

Greenblatt, J. A. AND J. WitTer.

1976. Behavioral studies on Malacosoma disstria (Lepidoptera: Lasiocampidae). Can. Entomol. 108: 1225-1228.

JoNES, R. E.

1977. Search behaviour: a study of three caterpillar species. Behaviour 60: 237-259.

LaUX, W.

1962. Individuelle Unterschiede in Verhalten und Leistung des Ringelspinners, Malacosoma neustria (L.) Z. Angewandte Zoologie 49: 465-525.

MA, W-C.

1972. Dynamics of feeding responses in Pieris brassicae Lin. as a function of chemosensory input; a behavioral, ultrastructural and electrophysiological study. Med. Landbouwhogeschool Wageningen 72-11: 1-162.

MYeRs, J.

1978. A search for behavioral variation in first and last laid eggs of western tent caterpillars and an attempt to prevent a population decline. Can. J. Zool. 56: 2359-2363.

Papaj, D. R. and M. D. Rausher.

1983. Individual variation in host location by phytophagous insects. In Ahmad, S. (ed) Herbivorous insects: host-seeking behavior and mechanisms. Academic Press (New York). 77-124.

Reynolds, S. E., M. R. Yeomans, W. A. Timmins.

1986. The feeding behaviour of caterpillars (Manduca sexta) on tobacco and artificial diet. Physiol. Entomol. 11: 39-51.

WeINER, J. AND O. T. SOLBRIG.

1984. The meaning and measurement of size hierarchies in plant populations. Oecologia 61: 334-336.

Wellington, W. G.

1957. Individual differences as a factor in population dynamics: the development of a problem. Can. J. Zool. 35: 293-323.

WiLson, E. O.

1971. The insect societies. Belknap Press (Cambridge, MA). 548. 

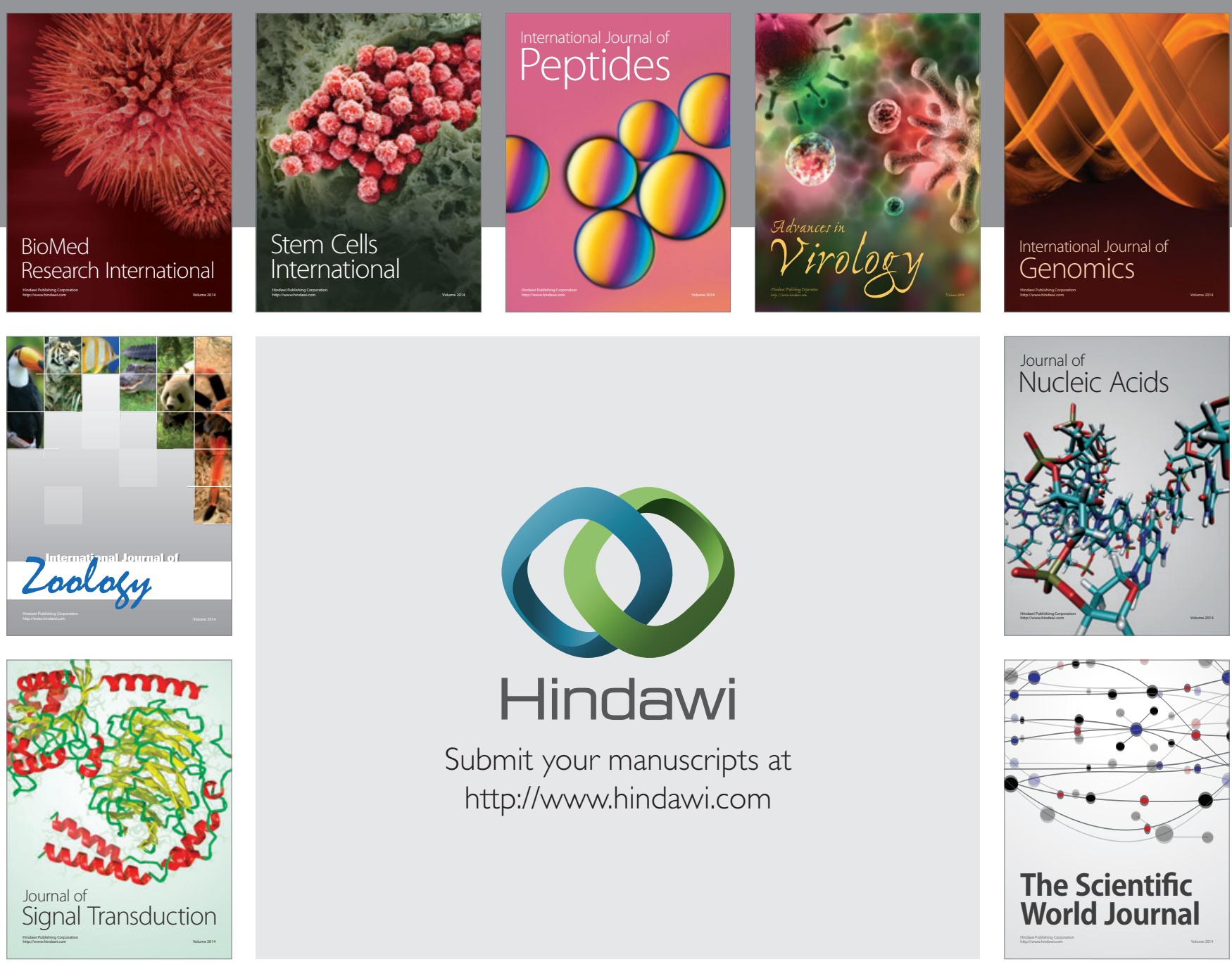

Submit your manuscripts at

http://www.hindawi.com
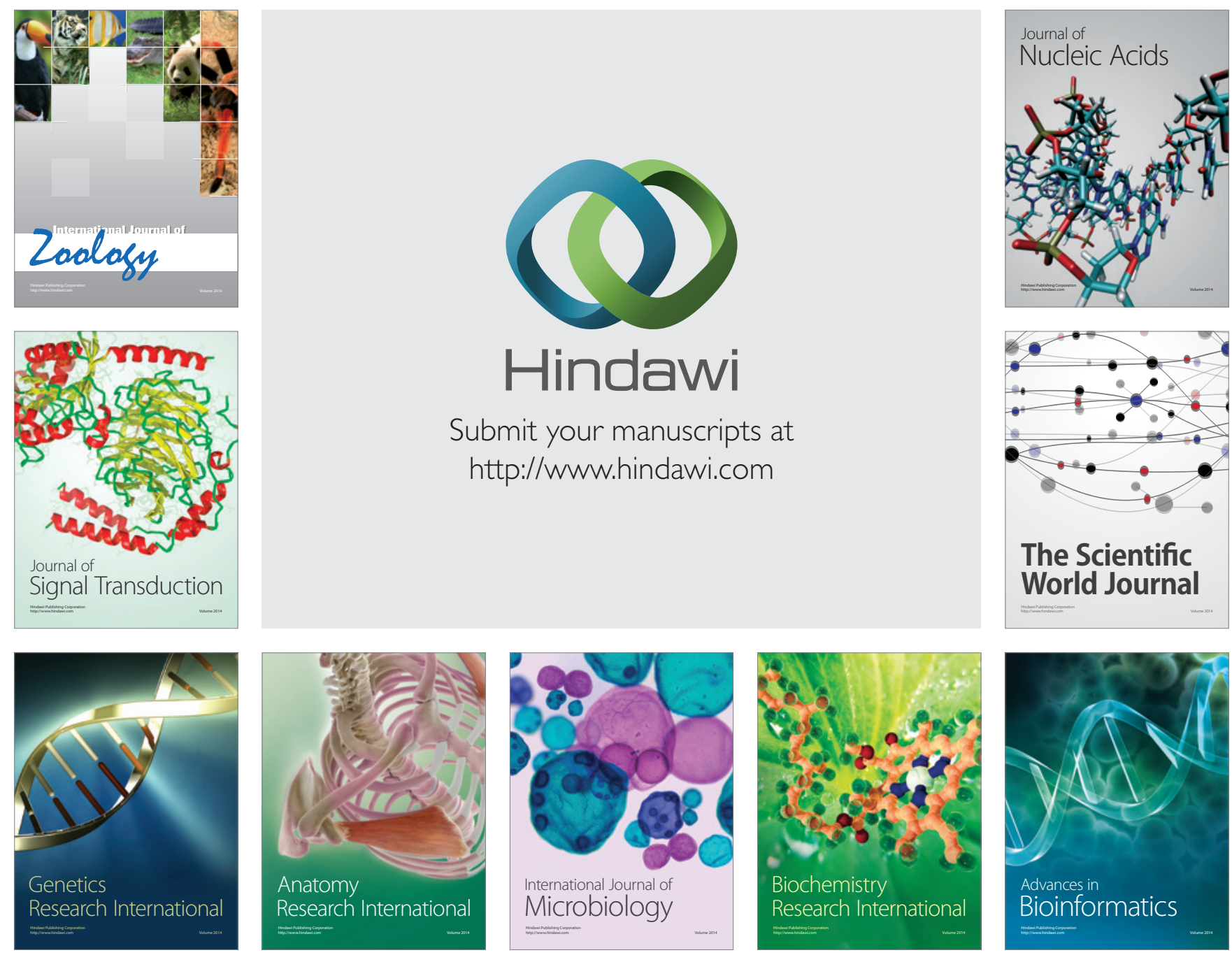

The Scientific World Journal
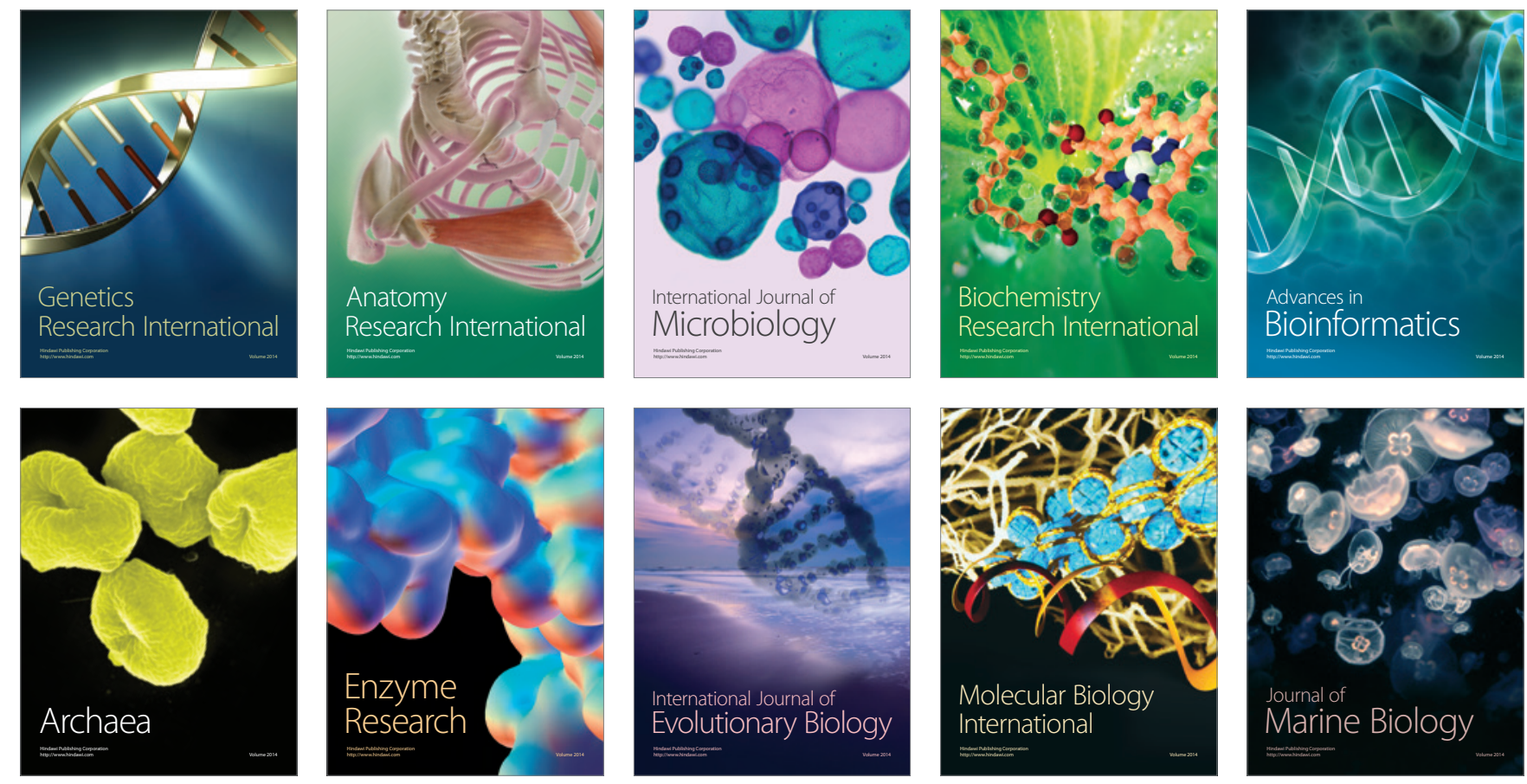